\title{
Direitos Humanos e Empresas: teorias, práticas e desafios metodológicos
}

\section{Human Rights and Business: theories, practices and methodological challenges}

\author{
Ana Luiza da Gama e Souza \\ Lara Denise Góes Da Costa \\ Letícia Helena Medeiros Veloso ${ }^{3}$
}

\section{RESUMO:}

No novo cenário de atividade econômica globalizada, Estado é parte necessária do processo e isto compromete profundamente a sua função de garantidor dos direitos fundamentais e dos direitos humanos, entretanto, as violações de direitos não são mais provocadas exclusivamente pelo Estado, diante da expansão do espaço econômico, como as corporações transnacionais ou globais. Neste contexto, pensar em corporações e direitos humanos e nas metodologias possíveis para estudar tal relação pressupõe, primeiro, uma contextualização acerca do lugar, hoje, das empresas e corporações na sociedade global, bem como das formas de regulação existentes e sob discussão. Este artigo analisou inicialmente o Marco Ruggie e seus princípios fundamentais de proteção, respeito e remediação, definindo os deveres de prevenção, investigação, punição e reparação de violações aos direitos humanos as que se referem a relação entre o Estado e as empresas e dando maior atenção a definição do conteúdo e dos limites das obrigações das corporações. Em seguida, analisou-se os paradoxos e os dilemas de responsabilidade e responsabilização corporativa a partir de dados extraídos da Global Compact (GC) - rede global de empresas comprometidas com princípios de direitos humanos. Em um terceiro momento, analisou as principais teorias contemporâneas acerca da relação Direitos Humanos e Empresas e a importância da Sociologia Econômica como área que ajuda à compreensão das instituições econômicas. Por fim, este trabalho apontou os desafios metodológicos e possíveis avanços, entre os quais forma sugeridos a ênfase no impacto social,

\footnotetext{
${ }^{1}$ Doutora em Filosofia pelo Programa de Pós-graduação em Filosofia da UFRJ. Professora titular da Universidade Estácio de Sá e professora do Programa de Pós-graduação em Direito - PPGD/UNESA. Graduação em Filosofia pela UFRJ e em Direito pela Universidade Cândido Mendes. Coordenadora do grupo de pesquisa ODIHH (Observatório de Direitos Humanos), parceiro da UFF e do Instituto de Direitos Humanos da Universidade de Connecticut / USA. Membro da Global Business and Human Rights Scholars Association (BR2R), do European International Studies Association e da Research Data Alliance (RDA).

${ }^{2}$ Professora do Programa de Pós-Graduação em Segurança Internacional e Defesa da Escola Superior de Guerra/ Ministério da Defesa. Pós-doutorado em Direitos Humanos pelo PNPD/CAPES do Programa de Pós-graduação em Direito e Evolução social da Universidade Estácio de Sá. Doutorado em Filosofia pela UFRJ. Doutorado em Ciências Sociais pela PUC- RIO. Coordenadora do grupo de pesquisa em Direitos Humanos -ODIHH (Observatório de Direitos Humanos) da Universidade Estácio de Sá, em parceria com a UFF e a Universidade de Connecticut / USA.

3 Possui graduação em Comunicação Social pela Pontifícia Universidade Católica do Rio de Janeiro (1991), mestrado em Antropologia - University of Chicago (1997) e doutorado em Antropologia - University of Chicago (2003). Professora Adjunta do Departamento de Sociologia e do Programa de Pós-Graduação em Sociologia e Direito da Universidade Federal Fluminense.
} 
político ou econômico da atuação de empresas no que diz respeito ao maior ou menor risco de violações de direitos humanos, a diversidade regional e o tamanho da empresa como variáveis relevantes a serem articuladas na pesquisa com uma tal metodologia cruzada que poderia construir um panorama analítico amplo o suficiente para conseguir apontar incongruências e dilemas, mas também casos possíveis de sucesso.

\title{
PALAVRAS-CHAVE:
}

Direitos Humanos; Metodologias; Empresas

\begin{abstract}
:
In the new scenario of globalized economic activity, the State is a necessary part of the process and this deeply undermines its role as guarantor of fundamental rights and human rights, however, violations of rights are no longer caused exclusively by the State, such as transnational or global corporations. In this context, thinking about corporations and human rights and the possible methodologies to study this relationship presupposes, first, a contextualization about the place, today, of companies and corporations in the global society, as well as of the existing forms of regulation and under discussion. This article initially analyzed Marco Ruggie and his fundamental principles of protection, respect and remediation, defining the duties of prevention, investigation, punishment and reparation of human rights violations that refer to the relationship between the State and the companies and giving more attention the definition of the content and limits of corporate obligations. Next, we analyzed the paradoxes and dilemmas of corporate responsibility and accountability based on data extracted from the Global Compact (GC) - a global network of companies committed to human rights principles. After that, this article analyzed the main contemporary theories about the relation between Human Rights and Companies and the importance of Economic Sociology as an area that helps the understanding of economic institutions. Finally, this paper pointed to the methodological challenges and possible advances, among which the emphasis is suggested on the social, political or economic impact of the companies' actions with respect to the greater or lesser risk of human rights violations, as well as relevant variables such as regional areas and the size of the company to be articulated in the research with such a cross-methodology that could construct an analytical panorama broad enough to be able to point out incongruities and dilemmas, but also possible cases of success.
\end{abstract}

\section{KEYWORDS:}

Human Rights; Methodologies; Business. 


\section{INTRODUÇÃO: EMPRESAS, CORPORAÇÕES E DIREITOS HUMANOS}

Pensar em corporações e direitos humanos e nas metodologias possíveis para estudar tal relação pressupõe, primeiro, uma contextualização acerca do lugar, hoje, das empresas e corporações na sociedade global, bem como das formas de regulação existentes e sob discussão. Em segundo lugar, envolve também certo esforço analítico: está-se falando de violações de direitos humanos, dos modos como as empresas/corporações vêm se posicionando face à ideia de direitos humanos, ou das formas de regulamentação das práticas empresariais visando minimizar desrespeitos e violações e, preferencialmente, propor formas de reparação em casos de violações?

Quanto ao primeiro ponto, cabe lembrar que a economia mundial mudou muito sua organização e governança nas últimas décadas, em especial nas esferas do comércio internacional e da organização da indústria. Por um lado, as diferentes partes do processo de produção são fisicamente separados - separação geográfica - o que se convencionou chamar de fragmentação ${ }^{4}$, permitindo uma rede transnacional de produção e por outro lado, ocorre a integração do mercado global, o que significa a integração funcional e a coordenação das atividades econômicas no mundo. A desintegração vertical ou desfragmentação das Corporações Transnacionais (CTN) decorre da redução de atuação direta da empresa nas atividades não centrais e no foco na inovação tecnológica, nas estratégias de produtos, de marketing e segmentos de manufatura e serviços, colocando em xeque o modelo fordista de integração vertical, no qual os diferentes processos de produção são controlados pela mesma empresa.

Este processo tem sérias implicações na realidade socioeconômica dos Estados. Por um lado, estas empresas planejam e executam a produção, comercialização e a distribuição de bens e serviços por referência à economia mundial e o país onde exercem sua atividade tem pouca importância no conjunto de sua estratégia. Por outro lado, Saskia Sassen ${ }^{5}$ (2010) argumenta que a globalização é um processo que ocorre também em nível subnacional, envolvendo redes e entidades transfronteiriças que conectam diversos processos e atores locais

\footnotetext{
${ }^{4}$. Gereffi, Gary., Humphrey, John et. al. (2005a) The governance of global value chains. Review of International Political Economy 12:1 February 2005: 78-104. ISSN 1466-4526 online C _ 2005 Taylor \& Francis Ltd. Routledge.

${ }^{5}$ Sassen, Saskia. Sociologia da globalização. (2010) Tradução de Ronaldo Cataldo Costa. Ed. Artmed. Porto Alegre.
} 
ou nacionais, dentre elas as $\mathrm{ONG}^{\prime}$ s de direitos humanos, por exemplo. Neste sentido, a atividade econômica globalizada reformula as ordens existentes e contribui para a formação de novas ordens e isto se dá por meio da prática de atores econômicos como as empresas transnacionais ou globais e os mercados globais e do desenvolvimento de determinados regimes de valor, como a desregulação da economia.

Neste novo cenário, por um lado, o Estado é parte necessária do processo de globalização econômica e isto compromete profundamente a sua função de garantidor dos direitos fundamentais e dos direitos humanos. Por outro, as violações de direitos não são mais, se é que alguma vez já o foram provocadas exclusivamente pelo Estado, diante da expansão do espaço econômico, mas por atores privados, como as corporações transnacionais ou globais.

Já quanto ao segundo ponto, lembremos que as violações aos direitos humanos por empresas e, a partir da década de 90, principalmente as corporações transnacionais, levaram a conscientização social e política sobre o impacto da atividade das empresas sobre os direitos humanos, atraindo a atenção dos Organismos Internacionais, em especial das Nações Unidas, que foi convocada a desenvolver mecanismos destinados a exigir das corporações transnacionais o respeito aos direitos humanos na realização de suas atividades, abrindo espaço também para o debate teórico acerca das obrigações e consequente responsabilidade das corporações com os direitos humano, obrigações/responsabilidade tradicionalmente atribuídas ao Estado.

Para enfrentar este desafio, agravado pela falta de regulação global das empresas por conta da fragmentação de suas atividades, em 2005 o Secretário-Geral da ONU nomeou John Ruggie como representante especial na temática dos direitos humanos e empresas, atribuindo a ele a função de investigar mais a fundo sobre as violações e então estabelecer um marco inicial de responsabilização, o que só foi concluído e avalizado pelo Conselho de Direitos Humanos da ONU em 2011.

Nos seis anos em que permaneceu como representante da ONU sobre direitos humanos e empresas, Ruggie produziu uma dezena de relatórios que mostram a evolução de seu trabalho, que se deu em três fases. Na primeira Ruggie foi convocado a identificar e esclarecer sobre as 
normas e as práticas existentes naquele contexto, através de um amplo programa de investigação sistemática, que se estendeu até a conclusão do último relatório ${ }^{6}$.

Na segunda fase, iniciada em 2007, Ruggie foi convidado a formular recomendações, com base nas investigações conduzida até então, o que fez em 2008 recomendando que o Conselho de Direitos Humanos da ONU apoiasse o marco inicial na temática dos direitos humanos e empresas, os três princípios fundamentais que ele havia desenvolvido: a) a obrigação do Estado de proteger contra abusos aos direitos humanos ${ }^{7}$, respeitá-los e realiza-los; b) a obrigação das empresas, como órgãos especiais da sociedade, de agir com diligência e respeitar todas as leis e os direitos humanos e c) que os direitos humanos e as obrigações tenham disponíveis mecanismos aptos a garantir o acesso das vítimas a meios de reparação efetivos, ou seja, meios de remediar os danos causados. Todos os princípios orientadores elaborados se assentam nestes três pilares.

Na última fase do mandato de Ruggie, o Conselho de Direitos Humanos da ONU, além de acolher e saudar o marco, prorroga o mandado até junho de 2011, incumbindo Ruggie de formular recomendações concretas e práticas para sua implementação, mas forma de princípios orientadores, objeto do último relatório desenvolvido por $\mathrm{ele}^{8}$, fruto de extensos debates com todos os grupos interessados, como governos, empresas, associações empresariais, sociedade civil e especialistas de diversas áreas da política e do direito, refletindo um diálogo aberto com todos os interessados na efetiva implementação do marco Ruggie.

O marco Ruggie marca uma nova fase no tratamento do problema da responsabilidade das corporações transnacionais e outras empresas com os direitos humanos, estabelecendo uma plataforma inicial para guiar as ações e iniciativas no sentido de comprometer cada vez mais as

\footnotetext{
${ }^{6}$ Na primeira fase Ruggie estabeleceu padrões de mapeamento de alegados abusos dos direitos humanos por parte de empresas, padrões de evolução das normas internacional sobre direitos humanos e direito penal internacional; investigou as novas práticas emergentes dos Estados e das empresas e avaliou as observações e comentários dos órgãos das Nações Unidas sobre as obrigações dos Estados nos abusos dos direitos humanos relacionados às empresas, dentre outras atividades. Cf. em: https://www.ohchr.org/EN/Issues/Business/Pages/Reports.aspx\#srepresentative.

${ }^{7}$ Também a responsabilidade por terceiros, ou seja, de obrigação de proteger também contra danos provocados por empresas com atividades em seu território.

${ }^{8}$ United Nations. Human Rights Council. (2011). Report of the Special Representative of the Secretary-General on the issue of human rights and transnational corporations and other business enterprises, John Ruggie: Guiding Principles on Business and Human Rights: Implementing the United Nations "Protect, Respect and Remedy" Framework. Doc ONU A/HRC/17/31, 21 Mar. Available at: http://www.businesshumanrights.org/media/documents/ruggie/ruggie-guiding-principles-21-mar-2011.pdf
} 
empresas com as obrigações de direitos humanos. O próprio Conselho de Direitos Humanos da ONU reconhece que:

The Guiding Principles' normative contribution lies not in the creation of new international law obligations but in elaborating the implications of existing standards and practices for States and businesses; integrating them within a single, logically coherent and comprehensive template; and identifying where the current regime falls short and how it should be improved. Each Principle is accompanied by a commentary, further clarifying its meaning and implications ${ }^{9}$.

No seu último informe, Ruggie desenvolveu mais profundamente os princípios fundamentais de proteção, respeito e remediação, definindo os deveres de prevenção, investigação, punição e reparação de violações aos direitos humanos, fazendo recomendações mais precisas sobre as obrigações de direitos humanos dos Estados e as que se referem a relação entre o Estado e as empresas e dando maior atenção a definição do conteúdo e dos limites das obrigações das corporações.

O Centro de Pesquisas em Direitos Humanos e Empresas ${ }^{10}$ apresentou um relatório em 2018 no qual apresenta resultados sobre respostas de 27 empresas - 15 do setor químico - a respeito de 17 casos de violação de direitos humanos. O relatório aponta que $79 \%$ dos casos se referem a violações extraterritoriais - o que implica em um desafio global - e que a grande maioria das violações ocorre na Ásia e África. Mostra ainda o relatório 50\% dos casos associados a exposição a substâncias químicas prejudiciais à saúde ocorrem na supply-chain, o que significa que ocorrem ao longo de toda a cadeia produtiva, deste os fornecedores de insumos, passando pela comercialização dos produtos, até a utilização pelo consumidor.

A partir de um estudo de casos concretos, o Centro de Pesquisas em Direitos Humanos e Empresas analisa as principais iniciativas das empresas e de organizações e conclui que apenas algumas empresas têm a devida diligência com os direitos humanos em suas cadeias de suprimentos e também que a relação entre a utilização de produtos químicos, a saúde humana e os impactos ambientais não são tratados de forma holística e rigorosa.

\footnotetext{
${ }^{9}$ Idem. p. 5.

${ }^{10}$ Disponível em https://www.business-

humanrights.org/sites/default/files/BHRRC\%20Chemical\%20Briefing\%2030\%20Jan\%202018.pdf.
} 
Ruggie $^{11}$ também reconhece que só iniciativas voluntárias não são suficientes para compelir as empresas a ajustar suas atividades aos direitos humanos e desconfia também que obrigações postas por tratados também são pouco efetivas ${ }^{12}$. A falta de efetividade das iniciativas voluntárias se dá, em primeiro lugar, por conta do poder do mercado, que no caso do setor agroalimentar é ainda maior. Neste sentido, Howard ${ }^{13}$ argumenta que justamente porque todas as pessoas dependem necessariamente dos alimentos é que este setor vem sendo caracterizado pelas megafusões como estratégia para aumentar violentamente seu poder de controlar o que se come.

Em segundo lugar, Ruggie argumenta que também em virtude do poder que detém as iniciativas das empresas são determinadas por elas mesmas, inclusive na escolha de quais os padrões de direitos humanos irão seguir, como também a própria definição destes padrões. Já os mecanismos externos de accountability, quando existentes, também vêm se mostrando insuficientes, pela mesma razão. O que, por sua vez, torna ainda mais complexa a tarefa daqueles pesquisadores interessados em mapear, analisar e compreender de que maneira as empresas e corporações, hoje, estão atentas ao que significariam "direitos humanos" e qual a relação destes com a própria empresa, sua atividade-fim, seus stakeholders e seu público-alvo. Deveriam as empresas se antecipar, por assim dizer, e proteger os direitos humanos de todos aqueles com quem se relacionam, de forma preventiva? Deveriam ter bons mecanismos de proteção dos direitos e necessidades tanto de seus públicos-alvo quanto de todos os possíveis afetados por suas atividades? Deveriam ter programas de promoção de direitos humanos, de forma específica ou geral? E quais os mecanismos de reparação, antecipados e a posteriori, que deveriam existir, considerando que os impactos (negativos) das empresas nem sempre podem ser previstos? Estas e outras questões têm estado nas pautas de discussão, tanto de institutos como o Centro de Pesquisas em Direitos Humanos e Empresas, quanto pelas próprias empresas.

\footnotetext{
${ }^{11}$ Ruggie, John G. (2013). Roundtable on implementing the UN Guiding principles on business and human rights. Thomas J. Dodd Research Center. University of Connecticut. USA.

${ }^{12}$ Porque tratados complexos são de negociação demorada e tem mecanismos de implementação pouco efetivos.

${ }^{13}$ Howard. Philip H. (2016.) Concentration and power in the food system: who control what we eat? Bloomsbury. Publishing. New York. p.13.
} 


\section{RESPONSABILIDADE SOCIAL CORPORATIVA (RSC) OU RESPONSABILIDADE SOCIAL EMPRESARIAL: DILEMAS E PARADOXOS}

A responsabilidade social corporativa $(\mathrm{RSC})^{14}$, a seu turno, ainda é o instrumento corporativo dominante, mas enfrenta um desafio perene: a dificuldade de conciliar a necessária redução de custos e ampliação do lucro, privilegiadas pelos acionistas face aos processos correntes de globalização e internacionalização, com a implementação de práticas empresariais mais humanas, justas e respeitosas dos direitos humanos de todos em suas diversas dimensões. Ou seja, existe uma ambiguidade, se não mesmo uma contradição, inerente ao próprio conceito: uma vez que a empresa, por definição, não pode prescindir da busca pelo lucro, enquanto se conceber "lucro" e "respeito aos direitos humanos" são antagônicos, o próprio conceito de RSC será ambivalente e de difícil, se não impossível, de ser resolvido.

Some-se a isso o fato de que as próprias definições do que sejam "direitos humanos" e de como se deveria respeitá-los, promove-los, ou protege-los, sejam complexas, pois há grande variedade no modo como grandes, médias e pequenas empresas trabalham com esta noção, tanto internamente, no Brasil, quanto em escala global. Para algumas empresas, "direitos humanos" são um termo quase guarda-chuva que poderia ser, quase, traduzido por "respeito ao ser humano", o que quer que queiramos entender por esta frase. Nesses casos, praticamente não se coloca a questão do que constituiria, exatamente, "respeitar direitos humanos"; bastaria a empresa se autodefinir como uma organização que incorpora a preocupação com o elemento humano em suas práticas. Já em outros casos, percebe-se maior preocupação em definir do que consistiriam exatamente em "direitos humanos", "respeito aos direitos humanos", e/ou "proteção aos direitos humanos"; percebe-se, nestes casos, uma certa preocupação de já integrar respeito, proteção e promoção de direitos humanos como parte da própria lógica empresarial.

\footnotetext{
${ }^{14}$ É grande o número de diferentes definições de Responsabilidade Social Corporativa. Nesse sentido, optamos pela definição da Ethics Performance, segundo a qual a RSC é a responsabilidade de uma empresa pela totalidade de seus impactos, com a necessidade de incorporar os valores da sociedade em suas principais operações, bem como o tratamento do seu ambiente social e físico. Cf. em Dahlsrud. Alexander (2006). How corporate social responsibility is defined: an analysis of 37 definitions. Wiley Interscience. Available at https://onlinelibrary.wiley.com/doi/epdf/10.1002/csr.132. p. 7
} 
Embora não seja obviamente consequência necessária de tal suposta humanização das práticas empresariais, a grande maioria de empresas e acionistas ainda considera que o aumento de custos seria inevitável. E, portanto, incorporar algum tipo de preocupação com direitos humanos no cerne da atuação empresarial iria contra os interesses comerciais da mesma, por definição. Assim, podemos dizer que, do ponto de vista do interior das empresas, todos são socializados para pensar suas práticas a partir de um ponto de vista corporativo, inviabilizando quaisquer decisões que poderiam ser vistas, a partir dessa percepção, como ignorando a lógica tradicional dos negócios - como seria o caso de qualquer preocupação mais profunda, séria, com o respeito, promoção e proteção de direitos humanos em alguns dos principais, ou preferencialmente todos, os aspectos empresariais. ${ }^{15}$

Ampliando mais ainda o debate, Wheeler ${ }^{16}$ denuncia que RSC é um instrumento de gestão cuja finalidade é evitar danos na reputação da empresa. Os planos e estratégias de RSC da Monsanto Global, por exemplo, são guiados por sua política de Direitos Humanos, ${ }^{17}$ que estabelece nove elementos ${ }^{18}$ de direitos humanos a serem respeitados pela empresa, a grande maioria referente aos direitos já reconhecidos pelas empresas em geral desde 2007. ${ }^{19}$ Porém, no relatório de sustentabilidade que a empresa acaba de apresentar ${ }^{20}$, ao tratar do item que se refere aos direitos humanos ${ }^{21}$, a empresa defende a segurança das tecnologias de manipulação genética (OGM), bem como de pesticidas como glifosato e Dicamba - o que, portanto, estaria de acordo com uma política de respeito aos direitos humanos - porém, ao fundamentar sua argumentação, os dados apresentados se baseiam em afirmações genéricas, justificadas a partir de dados não especificados, todos compilados em bancos de dados não informados. ${ }^{22}$

\footnotetext{
${ }^{15}$ Connoly, Nicholas; Kaisershot, Manette. (2016). Corporate power and human rights. Introduction. Routledge. New York. USA.

${ }^{16}$ Wheller. P. S. (2016). Global Production, CSR and Human Rights: The Courts of Public Opinion and the Social License to Operate. In Connoly, Nicholas; Kaisershot, Manette. Corporate power and human rights. Routledge. New York. USA. p. 10

${ }^{17}$ Conferir em https://monsanto.com/company/commitments/human-rights/

${ }^{18}$ É exatamente esta a expressão utilizada.

${ }^{19}$ Unites Nations. Implementation of General Assembly Resolution 60/251 of 15 march 2006 entitled "Human Rights council" Report of the Special Representative of the Secretary-General on the issue of human rights and transnational corporations and other business enterprises* Addendum Business recognition of human rights: Global patterns, regional and sectoral variations. A/HRC/4/35/Add.4 8. Available at https://documents-ddsny.un.org/doc/UNDOC/GEN/G07/111/64/PDF/G0711164.pdf?OpenElement.

${ }^{20}$ Monsanto Corporation. (2017). Growing better together. Sustainable Report. Executive Summary.

${ }^{21}$ Idem. p. 18

${ }^{22}$ Idem. p. 54.
} 
Nesse sentido, apenas informar que possui uma política de respeito aos direitos humanos não é certamente suficiente, pois não se pode verdadeiramente saber o quanto tais dados são cientificamente verdadeiros, permitindo que se deduza que, realmente, os direitos à saúde da população, por exemplo, estão sendo respeitados.

Apesar das críticas à insuficiência das iniciativas voluntárias como forma de comprometer as empresas com os direitos humanos, é certo que o comprometimento com boas práticas empresariais - práticas de acordo com standards de direitos humanos - já está se tornando uma realidade, pelo menos ao nível dos debates, das iniciativas por parte das próprias empresas, e das tentativas de regulamentação. A Global Compact (GC) - rede global de empresas comprometidas com princípios de direitos humanos - conta hoje com 4530 empresas participantes. No Brasil, 762 empresas participam do GC $^{23}$, sendo 17 do setor de indústrias químicas, um dos setores mais poderosos do mercado. Em 2016, o $5^{\circ}$ Fórum da ONU sobre Negócios e Direitos Humanos trouxe um debate inovador sobre a imersão dos direitos humanos nas regras e relacionamentos que impulsionam a economia ${ }^{24}$. No ano de 2018 o Projeto Shift e o Conselho Mundial de Empresas para o Desenvolvimento Sustentável (WBCSD) apresentam estudo de quinze casos reais de como as empresas estão contribuindo para os objetivos de desenvolvimento sustentável. Ressalta-se o exemplo de uma rede de marcas e varejistas provenientes da cadeia de suprimentos de frutos do mar na Tailândia que estão coordenando com processadores locais, produtores, sindicatos, ONGs e atores governamentais para aumentar a transparência, fomentar o engajamento multisetorial e estimular a mudança em toda a indústria. $^{25}$

Em paralelo às propostas de natureza voluntarista, o Conselho de Direitos Humanos da ONU propôs em 2014 a criação de um tratado vinculante para regular as atividades das corporações transnacionais e outras empresas, a partir dos princípios orientadores de Ruggie, estabelecendo para tal um grupo de trabalho intergovernamental (Resolução 26/9). O recente relatório do grupo de trabalho para a América Latina e Caribe ${ }^{26}$ mostra que o debate entre as diversas delegações é bem acirrado e não parece estar perto de um consenso. No entanto, houve

\footnotetext{
${ }^{23} \mathrm{Cf}$. em https://www.unglobalcompact.org/interactive

${ }^{24} \mathrm{https} / / / \mathrm{www}$. ohchr.org/EN/Issues/Business/Forum/Pages/2016ForumBHRStat.aspx

${ }^{25} \mathrm{Cf}$. em https://www.shiftproject.org/sdgs/

${ }^{26}$ United Nations. Human Rights Council. Thirty-seven session. Report on the third Session of the open-ended intergovernamental Working Group on transnational corporations and other business enterprises with respect to human rights. A/HRC/37/67, Available at https://digitallibrary.un.org/record/1474997.
} 
algum consenso, ao menos, em torno da ideia de que as empresas devem ter um impacto positivo nos direitos humanos, e que para tal é necessário um quadro de regulamentação obrigatória, o qual deve ser complementar aos princípios orientadores e não estar em oposição a eles. $^{27}$

\section{EMPRESAS E DIREITOS HUMANOS: TEORIAS, CONCEITOS E METODOLOGIAS}

Esta virada no sentido de reconhecer a necessidade de estabelecer standards de direitos humanos para guiar as atividades das empresas, guiando novas práticas, trouxe importantes desafios teóricos, conceituais e metodológicos para esta nova área de direitos humanos e empresas. Afinal, existe na teoria e filosofia políticas, além de outras disciplinas, longa trajetória de acúmulo de debates sobre o tema. O que são realmente "direitos humanos"? De quais "direitos humanos" estamos falando? Há categorias de "direitos" que são universais, ou seria preciso defini-los localmente, a partir das configurações sociais, políticas, históricas, econômicas e sociais de cada sociedade ou localidade ${ }^{28}$ E devemos falar em "implementação", "garantia", ou "luta" por direitos humanos? Qual seu alcance, e qual a relação entre direitos humanos e outras categorias, como por exemplo "participação política" ou "igualdade socioeconômica"?

Ainda, note-se que o debate acadêmico e as metodologias de pesquisa em direitos humanos vêm se desenvolvendo, nas últimas décadas, em torno de um crescente reconhecimento de sua interdependência em relação à política, aos movimentos sociais, às mudanças econômicas, à desigualdade, à moral, ao multiculturalismo, direitos das minorias e "políticas da diferença" nas sociedades contemporâneas, bem como ao direito e às relações internacionais, dentre outros. ${ }^{29}$ Note-se, ainda, que a investigação em direitos humanos precisa conjugar o local e o global em todas estes campos de conhecimento.

\footnotetext{
${ }^{27}$ Idem, p. 6

${ }^{28}$ Phillips, Anne. The Politics of the Human. The Seeley Lectures. Cambridge, Cambridge University Press. 2015.

${ }^{29}$ Benhabib, Seyla (2004). The Rights of Others: Aliens, Residents and Citizens. AU - Nic Craith, Máiréad. PY.
} 
Na década de 70 a pesquisa em direitos humanos era fundamentalmente uma pesquisa jurídico-normativa, centrada na criação e interpretação de normas e padrões internacionais de direitos humanos e ainda na criação de organismos internacionais voltados ao monitoramento das obrigações dos Estados. Nessa fase, o método utilizado era basicamente interpretativo, no sentido de alavancar, expandir e aprofundar estas normas e padrões. A partir dos anos 80, o direito ao desenvolvimento entra na agenda internacional com a Declaração sobre o direito ao desenvolvimento (1986) e a Declaração de Viena e Programa de Ação (1993) e esta nova fase alarga o campo da pesquisa dos direitos humanos para o estudo empírico do desenvolvimento, tendo como interesse investigativo os direitos humanos como o fundamento normativo para o desenvolvimento. Neste prisma, a pesquisa no campo dos direitos humanos abre a primeira porta para a interdisciplinaridade e para novas questões analíticas e metodológicas. O campo dos direitos humanos e desenvolvimento acirra o debate local x contextual, numa perspectiva comparada e o debate relativismo x universalismo, numa disputa de justificativas morais para os direitos humanos, neste novo espaço sociólogos e antropólogos voltam seus esforços para o desenvolvimento de novas perspectivas e ferramentas metodológicas.

Neste período, o avanço de uma política de mercado neoliberal e suas consequências para o aprofundamento das desigualdades engaja os economistas na investigação dos direitos humanos e desenvolvimento que contribuem com modelos de orientação prática para políticas de direitos humanos, partindo de métodos de avaliação causal do desempenho dos diversos atores do processo de desenvolvimento. A pesquisa em direitos humanos começa a pautar-se pela pesquisa empírica, ainda voltadas para o Estado, em metodologias baseadas em evidências e a partir dos anos 2000 cresce significativamente o número de pesquisas sobre indicadores e métodos de avaliação dos direitos humanos. ${ }^{30}$

A relação entre os padrões e normas de direitos humanos já estabelecidas e as que estão ainda em desenvolvimento, com as diversas demandas de direitos humanos em seus diversos contextos e dimensões tornam a interdisciplinaridade uma marca deste campo de investigação, que perpassa quase todos as áreas de conhecimento, em especial as ciências sociais e o direito. Neste sentido, os movimentos interdisciplinares e transdisciplinares

\footnotetext{
${ }^{30}$. Langford, Malcolm. Interdisciplinarity and Multimethod Research. In B.A. Andreassen, H.O. Sano and S. McIernet-Lankford, Human Rights Research Methods. University of Oslo Faculty of Law Research Paper No. 2016-30.
} 
caracterizam o estudo dos direitos humanos nas últimas décadas, em termos teóricos e metodológicos ${ }^{31}$

Por outro lado, a própria ideia de "direitos humanos" passou por vários refinamentos e aprofundamentos a partir de discussões sendo desenvolvidas na filosofia, filosofia política, teoria política, história e sociologia. Em discussão estão, principalmente, três problemáticas: (a) a quem se referem tais direitos e por que precisamos deles, e (b) com base nisto, como implementá-los (de "cima para baixo", via luta política e movimentos sociais, via leis e constituições?). Para os propósitos da presente pesquisa, é necessário elencar alguns dos debates mais importantes sobre o assunto, pois é em torno e a partir deles que se configuram os desafios e também as regulamentações tentadas no sentido de se garantir a proteção, o cumprimento e a promoção dos direitos humanos em contextos concretos - como é o caso das empresas aqui em questão.

Com relação ao primeiro ponto (a quem se referem os direitos humanos, e portanto, os direitos de quem estamos buscando implementar e/ou proteger), em “A Invenção dos Direitos Humanos: Uma História", Lynn Hunt (2009) retorna à Declaração de Independência americana, redigida por Thomas Jefferson, e à Declaração dos Direitos do Homem e do Cidadão da Revolução Francesa, procurando demonstrar a originalidade de ambos os documentos no que diz respeito à inauguração do conceito, desde então, "universalmente aceito", de que todos os seres humanos nascem livres, iguais e merecedores de certa dignidade inerente ao fato de serem humanos), "fato" este apontado já por Jefferson como "auto evidente". Ainda, diz Hunt (Ibid.), tornou-se então também universalmente aceita a ideia de que, uma vez que tais direitos são universais e inerentes à figura humana, eles devem ser protegidos e assegurados para todos os cidadãos.

Porém, a mesma Hunt argumenta que há, desde sempre, uma dupla ambiguidade em torno dessa suposta universalidade: primeiro, a de que nesses documentos iniciais a "totalidade" dos seres humanos se referia apenas a homens, brancos, com propriedade etc., e segundo, a de que por esse exato motivo "implementar direitos humanos" tem desde sempre significado ampliar sua ideia àqueles originalmente excluídos da formulação inicial. Hunt estende esse argumento inclusive à Declaração dos Direitos Humanos da ONU de 1948 que,

\footnotetext{
${ }^{31}$ Ibidem.
} 
segundo a autora, não conseguiu universalizar satisfatoriamente nem o conceito de direitos humanos, nem o conceito de ser humano a que esses se referem. Isto porque, segundo ela, embora as culturas, países, sociedades e grupos humanos sejam não apenas múltiplos internamente (e cada vez mais múltiplos hoje em dia), mas profundamente diferentes uns dos outros em suas particularidades, o documento da ONU ainda postula uma séria de características, valores e supostas necessidades humanas que, embora apresentadas como universais, são na verdade fortemente moldadas por valores ocidentais e modernos (Ibid.).

Isto, por sua vez, indicaria a necessidade de, em vez de se "tomar ao pé da letra" as definições de direitos humanos, ser humano e pessoa humana inerentes não só ao projeto de Ruggie, como também aos próprios projetos de implementação de "direitos humanos" por parte das empresas: de quais direitos se está falando? Por que se escolhe esses e não outros para direcionar as ações empresariais? Quais seus limites e possibilidades? E, acima de tudo, como as empresas estão elas mesmas lidando com tal diversidade de concepções, uma vez que grande parte delas opera em territórios supranacionais?

Já quanto ao segundo ponto (como implementá-los), em livro recente (2015) a cientista política Anne Phillips argumenta que, para entendermos como os "direitos humanos" se negociam no interior das sociedades, e como são (ou podem, ou devem, ser) implementados, precisamos compreendê-los como situados na interseção entre inclusão (e, portanto, igualdade) política (no sentido de que os direitos humanos têm a ver com a atribuição de igualdade a todos perante a lei e a cidadania) e inclusão (e, portanto, igualdade) econômica, no sentido de que, para além dessa igualdade política, os direitos humanos têm a ver com o suprimento de necessidades socioeconômicas, sem as quais a própria noção de cidadania não faz sentido.

Para a autora, dizer "direitos humanos" significa compreender que os seres humanos necessitam de direitos, e as sociedades, portanto precisam lhes garantir, tanto seu reconhecimento como cidadãos iguais perante a lei, a política, o voto etc., quanto o suprimento daquelas necessidades materiais e quase-materiais, como alimento, saúde, educação etc. No primeiro caso, estariam questões ligadas às características e demandas dos seres humanos calcadas em questões como proteção contra discriminações baseadas em gênero, raça ou etnicidade, proteção contra violências e preconceitos diversos, proteção da garantia do voto e da possibilidade de participação nas decisões políticas (via critérios universalizantes de 
cidadania e garantias de que os mesmos sejam garantidos em toda e qualquer sociedade). No segundo caso, aquelas questões referentes às necessidades socioeconômicas, como moradia digna, segurança alimentar, educação para todos, saúde garantida para todos, proteção ambiental, e assim por diante.

Em tempos recentes, tanto o debate acadêmico quanto o político têm tendido, segundo Phillips $^{32}$, seguindo Fraser ${ }^{33}$, a optar por um ou outro caminho, e portanto um ou outro conceito de direitos humanos: aquele calcado em demandas, necessidades e direitos políticos ou politicamente definidos, e aquele baseado em demandas por igualdade econômica, ou seja, maior equalização na distribuição dos recursos e consequente atendimento das necessidades materiais dos seres humanos em qualquer sociedade. Para Fraser, escolher entre uma ou outra opção - e para os propósitos desta pesquisa, entre um e outro conceito de direitos humanos que se buscaria implementar - seria um não debate, uma vez que tanto as demandas por inclusão política, visibilidade e reconhecimento dos seres humanos em suas diversas manifestações e especificidades (de gênero, raça, classe, geração, etnicidade, sexualidade, país de origem, religião etc.), quanto a necessidade de se construir necessidades mais justas economicamente e, portanto, mais igualitária, numa noção de inclusão não necessariamente alinhada com as tais "políticas da diferença".

Estendendo tal argumentação, o que ambas as autoras propõem é que "proteger", "respeitar" e "promover" (ou seja, "implementar") direitos humanos não pode prescindir de nenhuma dessas dimensões: a do reconhecimento dos diferentes seres humanos, individualmente ou em grupos, em suas particularidades cujas garantias estaria, portanto, incluída no próprio conceito de "direitos humanos", mas também a da redistribuição de recursos no seio de uma sociedade e entre os grupos, garantias essas (de acesso ao suprimento de necessidades materiais mas, acima de tudo, a uma distribuição mais igualitária de recursos na sociedade ${ }^{34}$ (Ibid.). Direitos, cidadania e direitos humanos, no entender dessas autoras, só se concebe nessa junção entre direitos políticos e direitos sociais (ou socioeconômicos). Isto significa que é necessário atentar para os modos como as empresas porventura nomeiam,

\footnotetext{
32 Op. Cit. Phillips, Anne. The Politics of the Human. 2015.

${ }^{33}$ Fraser, Nancy. Justice Interruptus. Critical Reflections on the "PostSocialist" Condition. London, Routledge, 1997.

${ }^{34}$ Ibidem
} 
diferenciam e buscam implementar um conceito de direitos humanos que seja tanto político quanto socioeconômico, bem como quais práticas de implementação são propostas.

Continuando o raciocínio desenvolvido até aqui, as novas abordagens metodológicas ajudam a compreender as instituições políticas, jurídicas e econômicas em sua relação com os direitos humanos. Com relação às instituições econômicas, uma nova área da sociologia desponta na década de 80, a sociologia econômica, que pretende recolocar a economia nas relações sociais. Granovetter e Polanyi marcam o início desse novo movimento na sociologia, a nova sociologia econômica, que concebe a economia não como um mecanismo que funciona à margem da vida social, mas como um componente dela, que necessita ser compreendida exatamente assim.

Granovetter ${ }^{35}$ propõe, então, que a economia (e, por extensão, o mercado), deve ser entendida a partir de seu enraizamento (embeddedness) nas redes de relações sociais e propõe a análise, em nível micro, de casos concretos específicos, através da qual ataca os elementos centrais da teoria econômica. Para ele, relações sociais são a arena privilegiada para entender a dinâmica da vida econômica. Polanyi ${ }^{36}$ (2000), por sua vez, incorpora uma visão macro, segundo a qual os mercados são apenas um dos componentes da vida econômica, que não pode ser reduzida apenas ao mercado, já que é muito mais complexa, combinando formas diferentes de produção e circulação de bens.

A partir desde dois paradigmas a sociologia econômica se desenvolveu como campo voltado a compreender o mercado como instituição social, sujeita a uma dinâmica social. Vários modelos de análise dos mercados são desenvolvidos, $\mathrm{O}$ modelo de análise de redes como forma de mapear as relações sociais para compreender o mercado, analisando como as estruturas sociais transmitem informações de mercado, definem standards operacionais e geram confiança. Esta abordagem permite demonstrar como as relações entre atores ajuda a explicar, dentre outras coisas, o que estes atores farão, com quem estabelecerão trocas de bens e capital e a frequência com que estas transações de repetem.

\footnotetext{
${ }^{35}$ Granovetter, Mark. (2007). Ação Econômica e Estrutura Social: o Problema da Imersão. RAE - eletrônica, vol. 6, n. 1, janeiro-junho 2007.

${ }^{36}$ Polanyi, Karl. (2000). A grande transformação. Tradução Fanny Wrobel. Revisão Técnica Ricardo Benzaquen

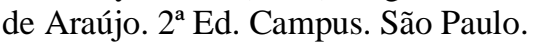


A perspectiva da economia política, a seu turno, tem como característica fazer a conexão entre estados, lei e mercados. Esta linha da sociologia econômica contribui com estudos comparativos dos arranjos capitalistas e seus efeitos para o desenvolvimento econômico dos estados. Assim sendo, as diversas abordagens de viés da economia política mostram que as relações entre governos, trabalhadores e capitalistas variam no tempo e geograficamente, o que significa, para esta linha teórica, que inexiste um só capitalismo, embora outras abordagens defendam justamente que estas diferenças tendem a diminuir até a formação de um capitalismo global.

O terceiro modelo é o institucionalista. Nesta abordagem o que define a estrutura social do mercado são, por um lado, os entendimentos informais e as molduras cognitivas e por outro lado, são as leis formais, as regulações e as ações dos Estados e das Cortes que modelam a estrutura do mercado. Para o primeiro grupo teórico os mercados são campos onde empresas observam-se umas às outras, imitando-se e criando nichos, para reproduzir suas posições no campo, enquanto que para o segundo, o mercado está ligado ao Estado que participa não só através das regras postas e das sanções aplicadas, mas também influencia na definição dos tipos de produtos que são apropriados para a troca no mercado. E neste sentido a teoria institucional também se ocupa com a dinâmica interna dos Estados e sua influência no modo como eles interferem no mercado.

\section{DESAFIOS E AVANÇOS METODOLÓGICOS: À GUISA DA CONCLUSÃO}

Com base no que vimos discutindo acima, parece claro que há uma série de desafios a serem transpostos por qualquer pesquisador/a que busque compreender (aspectos da) relação entre empresas e direitos humanos, principalmente a partir de casos concretos e empresas específicas, individualmente ou em grupos. O primeiro deles, obviamente, tem a ver com as diferenças nas concepções do que seja uma empresa, qual seu papel na sociedade, o que são "direitos humanos" e o quanto uma empresa deve se interessar por promover, respeitar e proteger tais direitos, de quem e sob quais condições, bem como quais as medidas de reparação cabíveis em casos de violações. Um segundo desafio, a partir daí, está na distância que pode 
existir entre discurso e prática, ou seja, determinada empresa pode se utilizar de um discurso sobre direitos humanos extremamente preocupado com o elemento humano e a necessidade de se ter seus direitos mais fundamentais sempre em mente nas práticas empresariais, mas suas práticas - e muitas vezes por conta da própria atividade-fim, como é o caso, por exemplo, de mineradoras, empresas de óleo e gás, cigarros etc. - têm profundos impactos sobre os direitos humanos de um sem número de indivíduos concretos. O terceiro desafio, claramente, tem a ver com a necessidade, porém dificuldade, de se medir, de alguma forma, quais os impactos - no caso daquelas empresas que, além do discurso, têm sólidas práticas relacionadas a direitos humanos - dessas práticas, tanto em respeito a respeitar, promover e proteger, quanto em relação aos modos de reparação.

Em termos gerais, gostaríamos de sugerir os seguintes caminhos para pesquisas em empresas e direitos humanos, considerando-se, sempre, os limites e possibilidades inerentes a cada aspecto a ser pesquisado. Em relação ao impacto social, político ou econômico da atuação de empresas, ou grupos de empresas, em direitos humanos, há que se levar em conta, inicialmente, o maior ou menor risco de violações de direitos humanos por conta da área da atuação da empresa. Poder-se-ia, assim, criar indicadores que estivessem relacionados ao maior ou menor risco dessa atividade e, ainda, considerar que, quanto piores as condições contextuais da atuação da empresa em relação a seu impacto negativo sobre os direitos humanos de indivíduos, grupos e, por vezes, regiões inteiras, maior seria o impacto positivo daquelas que possuem boas políticas de direitos humanos.

Outro ponto teria a ver com a questão da diversidade regional: esses mesmos indicadores, ou outros, poderiam ser organizados segundo a região, já que alguns tipos de impacto positivo das práticas de direitos humanos de determinadas empresas são mais identificados com contextos rurais (por exemplo, registro civil de nascimento, educação em direitos humanos, trabalho escravo, combate à tortura, proteção a defensores de direitos humanos), enquanto outros identificam-se mais com contextos urbanos, como seria o caso de impactos positivos ou negativos sobre relações de gênero, raça, pessoas com deficiência, criança e adolescente, pessoas idosas, populações LGBT e populações em situação de rua.

Ainda outro elemento a ser levado em consideração tem a ver como tamanho das empresas. Supostamente, uma empresa de pequeníssimo porte atuando na área, por exemplo, 
de alimentos ou cosméticos orgânicos em escala local teria impactos negativos muito menores sobre os direitos humanos daqueles indivíduos, grupos e regiões com os quais se relaciona, enquanto que uma empresa de médio porte do mesmo setor poderia incorrer em maior número de impactos negativos sobre direitos humanos (por exemplo, estabelecendo práticas mais ou menos adequadas, em termos de direitos humanos, no que diz respeito a relações com fornecedores ou com o meio ambiente), e uma empresa transnacional de grande porte, ainda na mesma área, embora essa área fim não fosse considerada inerentemente danosa aos direitos humanos (como seria o caso de tabaco, possivelmente mineradoras etc.), poderia potencialmente incorrer em maior número potencial de violações por conta da própria escala de sua atuação (por exemplo, o que constituiria "respeito" aos direitos humanos em seu próprio país poderia ser percebido como altamente prejudicial em outro país, com outra cultura e costumes. Nesse caso, teria que ser considerada também, com relação às empresas de grande porte, a extensão da supply-chain na pesquisa sobre boas práticas em direitos humanos naquelas atividades exercidas em outros Estados ou mesmo países.

Um outro ponto a ser considerado, claramente, seria a adesão espontânea a redes, pactos, ou outras configurações que reúnem conjuntos de empresas autodefinidas como particularmente interessadas em construir e consolidar boas práticas em direitos humanos, como por exemplo o Pacto Global - Rede Brasil - tendo em conta seu compromisso com a realização dos direitos humanos.

Em linhas gerais, todas essas particularidades teriam que ser levadas em consideração ao se propor metodologias de pesquisa para esse estudo sobre empresas e direitos humanos, em grande parte por conta das potenciais incongruências elencadas acima (distância discurso/prática, incompatibilidade potencial da atividade fim com boas práticas de direitos humanos, e dificuldade para se medir impactos concretos). É possível, porém, construir sólidas metodologias que deem conta desses problemas: por exemplo, levantando inicialmente dados concretos acerca da empresa em si (onde atua, como atua, qual seu organograma, onde está localizada a área responsável por Responsabilidade Social Corporativa e por direitos humanos etc.), identificando a seguir como essa mesma empresa define sua relação com direitos humanos, e só então procurando identificar, na pesquisa, se e como tais práticas são ou foram realmente implementadas. Só ao final dessas três etapas seria então possível verificar impactos sociais, econômicos e políticos concretos. 
Inicialmente, portanto, se poderia realizar um levantamento amplo e diversificado de tipos de empresas e formas de atuação em direitos humanos, conforme definido, por exemplo, pelos parâmetros da ONU, mas também pelas próprias empresas tal como formulado em seus relatórios e outros materiais de divulgação. A seguir, poderia ser feita uma pesquisa quantitativa com amostras de empresas, baseada em questionários, visando mapear, analisar e compreender (1) conceitos de direitos humanos utilizados, (2) processos de seleção quanto a esses conceitos e como e por que implementá-los, (3) processos de construção das práticas a serem implementadas e processos de gestão, acompanhamento e diagnóstico dessas mesmas práticas, por parte das empresas, e (4) impactos concretos de tais práticas, na medida em que seja possível medi-los a partir de relatórios, avaliações e diagnósticos elaborados pelas próprias empresas.

Obviamente, as perguntas e as opções de resposta teriam que ser construídas, no questionário, de forma a permitir uma série de cruzamentos (com relação a porte, região, setor etc., bem como aos diferentes marcadores sugeridos no edital do projeto (gênero, infância e juventude etc.), para permitir a construção de um panorama comparativo e, assim, uma melhor noção das motivações, desafios encontrados, outras limitações a serem superadas, e práticas de acompanhamento, controle e diagnóstico (medição de impacto) que (a) estão guiando a implementação de programas e práticas de direitos humanos por parte das empresas atuantes no Brasil e (b) poderão ser posteriormente cruzadas com dados relativos ao êxito de tais práticas (também coletados através de perguntas inseridas nos questionários; por exemplo, se e como a empresa quantifica o resultado de suas práticas, e quais são esses resultados (em número de pessoas atendidas, efeitos de tal atendimento sobre as vidas das pessoas etc.). Através de (a) e (b), se poderia construir então um panorama amplo de como quais empresas estão planejando, implementando, acompanhando e diagnosticando quais práticas, bem como os impactos (quantificáveis, passíveis de serem medidos e avaliados) das mesmas. Só assim seria possível avaliar, por exemplo, o que realmente a empresa faz e quais dessas práticas podem ser consideradas "exitosas” ou não.

Já quanto à noção de que não podemos partir de um conceito pré-definido de "direitos humanos" ao qual toda empresa atuante no país se adequa, parte importante de qualquer pesquisa é mapear, analisar e compreender o que cada empresa, ou cada grupo de empresas, compreende por direitos humanos. Isto porque, embora os parâmetros sugeridos por Ruggie e a ONU sejam bem estabelecidos - há uma série de direitos, organizados numa série de 
categorias, aos quais em princípio todas as empresas precisariam se adequar - na impossibilidade ou falta de interesse de algumas, muitas ou (quase) todas as empresas cumprirem à risca absolutamente todos os critérios, existe grande maleabilidade nas práticas de implementação das empresas com relação aos direitos humanos. Por um lado, porque os direitos que parecerão mais relevantes a uma ou outra empresa (e seus públicos) são dependentes do porte, do setor, da região em que atua e assim por diante. Por outro, porque, embora os parâmetros da ONU sugiram que se pense em direitos humanos, por parte das empresas, como algo que se deva respeitar, promover, proteger e reparar, "implementar" direitos humanos, para uma empresa, pode compreender um, alguns, ou todos estes quatro critérios.

Assim, cabe à pesquisa, primeiro, compreender os processos de seleção das empresas quanto àqueles direitos definidos pelos parâmetros da ONU que as mesmas devam priorizar em certo período de tempo, bem como suas razões para tais escolhas. Segundo, cabe à pesquisa compreender o que cada empresa entende por "implementar" direitos humanos, e como essas compreensões se encaixam nos ideais de respeito, promoção, proteção e reparação, bem como quais as relações que se pode traçar entre essas compreensões e os universos de atuação das empresas. Portanto, há que se considerar que as empresas, na impossibilidade de cumprirem simultaneamente com todos os requisitos dos parâmetros da ONU, selecionam aqueles para onde direcionarão suas práticas e seus investimentos de acordo com suas características próprias. Por exemplo, para uma empresa de grande do agronegócio a questão do trabalho escravo pode ser mais imediata do que questões de segurança pública, as quais por sua vez seriam mais imediatas para uma empresa menor localizada num contexto urbano.

Finalmente, quanto aos impactos concretos das práticas, na medida em que fosse possível medi-los a partir de relatórios, avaliações e diagnósticos elaborados pelas próprias empresas, teriam que ser analisados tanto o que o questionário permitisse identificar em termos de como quais empresas avaliam e produzem diagnósticos sobre o êxito (ou fracasso) de suas práticas em direitos humanos, quanto os materiais que essas empresas porventura tenham produzido sobre esses impactos (relatórios e outros possíveis materiais, a critério de cada empresa). Isto não para unicamente quantificar quantas empresas podem considerar quantas de suas práticas exitosas ou não, mas também para que os próprios pesquisadores pudessem analisar os resultados e avaliações produzidos por essas empresas. Na medida em que é difícil, se não impossível, definir o que é uma "prática exitosa" (exitosa para quem? Com base em 
quais critérios?), teria que ser utilizado um mecanismo de cruzamento entre o que as empresas dizem que fazem em termos de avaliação do resultado de suas práticas e aquilo que se pode verdadeiramente avaliar como tendo sido resultados das ações das empresas, na medida em que tais resultados estarão disponíveis em diversos materiais - os quais, inclusive, são necessários caso a empresa pretenda se manter enquanto signatária, por exemplo, do Pacto Global: há que se documentar o que foi alcançado em termos de resultados - ou seja, há que se documentar o "êxito" - das práticas em direitos humanos das empresas.

Desta forma, com uma tal metodologia "cruzada", se poderia construir um panorama analítico amplo o suficiente para conseguir apontar incongruências e dilemas, mas também casos possíveis de sucesso.

\section{FONTES E REFERÊNIAS BIBLIOGRÁFICAS}

BENHABIB, Seyla (2004). The Rights of Others: Aliens, Residents and Citizens. AU - Nic Craith. Máiréad . PY

CONNOLY, Nicholas; Kaisershot, Manette. (2016). Corporate power and human rights. Introduction. Routledge. New York. USA.

DAHLSRUD. Alexander (2006). How corporate social responsibility is defined: an analysis of 37 definitions. Wiley Interscience. Available at https://onlinelibrary.wiley.com/doi/epdf/10.1002/csr.132.

FRASER, Nancy. (1997). Justice Interruptus. Critical Reflections on the "PostSocialist" Condition. London, Routledge.

GEREFFI, Gary., Humphrey, John et. al. (2005) The governance of global value chains. Review of International Political Economy 12:1 February 2005: 78-104. ISSN 1466-4526 online C_ 2005 Taylor \& Francis Ltd. Routledge.

GRANOVETTER, Mark. (2007). Ação Econômica e Estrutura Social: o Problema da Imersão. RAE - eletrônica, vol. 6, n. 1, janeiro-junho 2007

HOWARD, Philip H. (2016.) Concentration and power in the food system: who control what we eat? Bloomsbury. Publishing. New York

HUNT, Lynn. A Invenção dos Direitos Humanos. Uma História. São Paulo, Companhia das Letras, 2009. 
LANGFORD, Malcolm. (2016) Interdisciplinarity and Multimethod Research. In B.A. Andreassen, H.O. Sano and S. McIernet-Lankford, Human Rights Research Methods. University of Oslo Faculty of Law Research Paper No. 2016-30

MONSANTO CORPORATION. (2017). Growing better together. Sustainable Report. Executive Summary.

PHILlIPS, Anne. (2015). The Politics of the Human. The Seeley Lectures. Cambridge, Cambridge University Press.

POLANYI, Karl. (2000). A grande transformação. Tradução Fanny Wrobel. Revisão Técnica Ricardo Benzaquen de Araújo. $2^{\mathrm{a}}$ Ed. Campus. São Paulo.

RUGGIE, John. (2007). Business and Human Rights: The Evolving International Agenda. KSG Faculty Research Working Paper Series; nº 29. June. 2007.

. (2013). Roundtable on implementing the UN Guiding principles on business and human rights. Thomas J. Dodd Research Center. University of Connecticut. USA.

SASSEN, Saskia. Sociologia da globalização. (2010) Tradução de Ronaldo Cataldo Costa. Ed. Artmed. Porto Alegre.

UNITED NATIONS. (2007). Human Rights Council. Implementation of General Assembly Resolution 60/251 of 15 march, 2006 entitled "Human Rights council" Report of the Special Representative of the Secretary-General on the issue of human rights and transnational corporations and other business enterprises* Addendum Business recognition of human rights: Global patterns, regional and sectoral variations. A/HRC/4/35/Add.4 8. Available at https://documentsddsny.un.org/doc/UNDOC/GEN/G07/111/64/PDF/G0711164.pdf?OpenEle ment.

. (2011). Human Rights Council. Report of the Special Representative of the Secretary-General on the issue of human rights and transnational corporations and other business enterprises, John Ruggie: Guiding Principles on Business and Human Rights: Implementing the United Nations "Protect, Respect and Remedy" Framework. doc ONU A/HRC/17/31, 21 Mar. Available at: http://www.businesshumanrights.org/media/documents/ruggie/ruggie-guiding-principles-21-mar-2011.pdf

. (2018). Human Rights Council. Thirty-seven session. Report on the third

Session of the open-ended intergovernamental Working Group on transnational corporations and other business enterprises with respect to human rights. A/HRC/37/67, Available at https://digitallibrary.un.org/record/1474997.

WHELLER. P. S. (2016). Global Production, CSR and Human Rights: The Courts of Public Opinion and the Social License to Operate. In Connoly, Nicholas; Kaisershot, Manette. Corporate power and human rights. Routledge. New York. USA.

Submetido em: 29/03/2019

Aceito em: 24/09/2019 